\title{
Study on Two-level Teaching Supervision Management of Higher Vocational Colleges Based on Teachers' Professional Development
}

\author{
Ying Huang ${ }^{1, a}$, Mingguang Liu' ${ }^{1, b}$ and Libin Wang ${ }^{2, c}$ \\ ${ }^{1}$ Guangzhou Civil Aviation College, Guangzhou 510403, China; \\ ${ }^{2}$ Guangdong Polytechnic Normal University, Guangzhou 510665, China; \\ ayingh89@163.com, bliumingguang@caac.net, c1462809009@qq.com
}

\begin{abstract}
This paper analyzes the importance and current situation of teachers' professional development as well as the present state of teaching supervision in higher vocational colleges. By taking Guangzhou Civil Aviation College as an example, this paper proposes the necessity of two-level teaching supervision management, college-level and associate school-level, and constructing a two-level teaching supervision system with common goals and good interactions is then presented. The findings can help guide teachers' professional development, promoting teachers' self-study and personal growth.
\end{abstract}

Keywords: Teachers Professional Development; Higher Vocational Colleges; Two Stages Teaching Supervision Management.

\section{基于教师专业发展的高职院校两级教学督导管理探析}

\author{
黄颖 ${ }^{1}$, 刘铭光 ${ }^{1}$, 王力涁 ${ }^{2}$ \\ 1 广州民航职业技术学院, 广州 中国; \\ 2 广东技术师范学院, 广州 中国
}

摘 要: 本文从教师专业发展的重要性及现状, 以及高职院校现有督导工作的现状进行分析, 以广州民航职业技术学院为例, 指出校院两级教学督导管理的必要性, 并提出构建目标一致、 良好互动的两级教学督导管理, 研究结果可用于指导教师专业发展, 促使教师自我学习、自 我提升。

关键词：教师专业发展；高职院校；两级督导管理。

\section{1. 前言}

教师决定学校的教学质量。教师的职业具有不可替代性, 有着独自的专业知识、专业技能和 专业精神, 其教学水平、发展状况会影响教师专业发展, 从而影响学校的教学质量。随着现 代社会的高速发展, 各高校要求教师具有崇高的师德、渊博的知识、扎实的教学功底和精益 求精的工匠精神，把 “提升教师专业素养、促进教师专业发展” 的内涵性建设作为重中之重。 那么, 如何才能有效促进教师专业发展呢? 国内各大高校纷纷建立了教学督导机制, 通过对 教师的 “督和导” ，了解教师任教的真实状况，同时调动他们教学的主动性、积极性和创造 性, 促使教师自觉选择专业发展, 推动自我学习、自我提升。本文以广州民航职业技术学院 为例, 就建立校院两级督导管理, 促进教师的专业发展进行探索实践, 以便为兄弟院校提供 范例。 


\section{2. 基于教师专业发展的两级督导管理的必要性}

2.1. 教师专业发展的重要性及现状

1. 教师专业发展的重要性

当今教育, 科技突飞猛进、信息与日俱增, 每个学科和学术分支的基础都在扩展, 并由单一 走向多元, 向更深更广的层面发展。与此同时, 教师的专业发展也必须与时俱进, 以适应教 育发展的需求。

2. 教师的专业发展现状

1）新入职教师对自身专业发展目标不明确, 处于模糊状态

以广州民航职业技术学院的教师为例, 新入职的教师多半来自中国民航大学、南京航空航天 大学等非师范类的高校或者航空公司等非教育行业的企业或公司。来自非教育行业的企业或 公司教师占全体教师的比例? 新教师, 尤其是刚结束学生生涯, 由学生的角色转变为教师的 大学毕业生, 入职后就角色上讲台讲课, 在进入教师角色之前, 几乎没有机会去观摩有经验 教师的教学, 教学对他们来说是一个挑战。他们可能对自己的教学能力缺乏自信, 也没有准 备好去适应学校环境和承担教学职责, 对于如何规划自己的专业发展路程更加就显得模糊。

2) 职业稳定期和受挫教师处于专业发展停滞状态

新教师经过几年的摸索和总结, 适应了学校的教学工作, 多数情况下, 已经获得长期的聘用, 人事政策不会对他们产生影响。此时, 职称成为了教师的专业指导, 职称评定条例成为他们 自主学习和发展的目标和标准, 处于积极学习状态。当教师获得职称后, 即处于职业稳定期, 或者受到挫折后处于解急状态, 很多评上职称的教师或者没有评上职称的教师, 就处于这种 状态, 他们认为我的奋斗目标已经达到, 或者受挫, 仅满足上好自己的课。他们的专业发展 几乎处于停滞状态。

此时, 教学督导就应运而生, 通过 “督” 和 “导” , 指导并促进教师专业发展, 形成了推动 教学管理民主化、规范化的一项有效措施。顾名思义, 督是指督促; 导是指引导、指导, 即 是在教学监控系统中, 对教学过程和教学质量的监督、检查、评价和指导等一系列活动。

高职院校教学督导的工作现状

教学督导的职责是配合教学主管部门的中心任务, 充分发挥其在教学管理与教学研究方面的 辅助作用, 监督教学、指导教学。就目前情况看, 教学督导队伍比较薄弱。

1. 教学督导人力组成过少

据了解, 国内高职院校基本都设有专门的校级督导机构, 校级教学督导人数一般在 $5-15$ 人 左右, 有的学校只有 $1-2$ 人, 如广州民航职业技术学院就只有三名专职督导员, 其中 2 名是 外聘督导。学校每学期开设课程涉及 25 个专业, 约 200 多门课程。因此, 要了解全校的教师 情况, 仅仅听课的工作量就很大, 为数不多的校级教学督导就显得人力不足了, 这样会造成 教学督导疲于听课, 疏于指导的情况出现。

2. 校教学督导所属学科及专业组成单一

教学督导由于人员组成较少, 从专业配置情况看, 教学督导的学科专业组成略显不足, 很多 学校的教学督导面临在自己专业以外的学科和领域开展工作。广州民航职业技术学院的二名 专职督导员, 就自己的学科专业特长分别负责飞机维修工程学院、航空港管理学院、经营管 理学院和人文社科学院的教学督导任务。教学督导员只能侧重课堂教学的共性来评价教师的 教学水平, 例如教学态度、教学方法、教学进度、教学内容的涃熟程度、逻辑思维、多媒体 的运用、教师与学生互动的效果以及学生出勤率等, 至于各个学科本身的教学内涵、规律性 的挖掘 就很难做出科学性、全面性的评价。因此, 会给学校整体的教学督导工作带来盲点。 3. 跨校区听课, 减低工作效率。广州民航职业技术学院有三个校区, 校区之间相隔较远, 督 导跨校区进行听课会耗费更多时间和精力, 事倍功半。

2.2. 建立学校、二级学院的两级督导管理的必要性

为更好对学校教师进行有效的专业发展指导, 建立学校和二级学院的两级教学督导管理很有 必要了。 
首先, 可帮助教师专业发展。二级学院可根据学院具体的专业需求, 分别在各专业、各学科 领域, 选拔和聘任有教学经验的学科带头人和优秀教师担任教学督导, 这样更能帮助教师明 确专业发展方向; 提升专业科研能力; 提高课堂教学水平。

其次, 可弥补学校教学督导人力的不足。二级学院教学督导的设立, 扩充了学校教学督导队 伍, 为学校教学督导全面、充分了解整体教学情况奠定了基础, 为更好的促进教师专业发展, 开展教学督导工作创造了条件。

最后, 可充分发挥二级学院的学科专业优势, 弥补学校教学督导所属学科领域专业对口的不 足。

\section{3. 构建有效的两级督导管理 促进教师专业发展}

校级教学督导侧重宏观方面, 院级教学督导侧重微观方面, 通过相互协作, 构成完整的教学 督导制, 不仅强化了教学督导的作用, 还增强了教学督导的力度。然而, 构建怎样的教学督 导制才能更好的促进教师专业发展?

2.3. 目标一致 各司其职

1. 听课范围。原则上, 二级学院教学督导职责是对所属二级学院的教师教学进行监督和指导, 只在所属的二级学院内部进行听课, 重点是对本院教学排名靠前、后十名教师、学校督导跨 校区听课中发现的教学质量以及教学效果好和差的教师进行听课。校级教学督导则是对全校 的教师的教学进行监督和指导。

2. 职责范围。二级学院教学督导的职责是承担对二级学院的教师所开设的课程全面进行检查、 督导。包括: 课程的设置、教材的选用、教学大纲和授课计划的制定、试讲、集体备课、试 卷的审查和批准、学生成绩的评定、学生论文的指导、教学态度和教学效果的认定等。而学 校教学督导的职责是在管辖校区内, 对教师所开设的课程, 根据具体情况或特殊要求, 进行 抽查性的检查和督导。

3. 督导的对象。二级学院教学督导面向二级学院的教师, 是二级学院领导了解本学院教师的 教学和科研情况, 与教师沟通的纽带和桥梁, 主要是把握二级学院的教学、科研情况, 促使 教师提升教学、科研水平, 较好的完成学校的教学任务。而校级教学督导则面向全校范围的 教师, 通过全校范围的督导工作, 了解整个学校的教学情况, 及时反馈给二级学院, 既是沟 通二级学院的纽带和桥梁, 也是学校领导把握、监控和指导全校教学的纽带和桥梁。

2.4. 良性互动 增强实效

学校、二级学院的两级督导存在一定的区别, 需明确分工, 各负其责。但并非 “楚河汉界”, 在工作中还需进行良好的沟通互动, 有必要的配合, 共同发挥督导作用。

1. 事前沟通。学校教学督导开展工作前, 要把本学年或本学期教学督导工作目标、工作计划、 工作方法和措施等, 与二级督导进行沟通, 起到相互了解的目的, 从而, 实现共同的目标。

2. 事中沟通。学校教学督导开展工作中, 在教学督导各个环节上要取得二级学院督导的支持 与配合;

3. 事后沟通。学校教学督导开展工作后, 要把督导结果向二级学院反馈, 提出意见或建议, 督促二级学院督导开展工作。

\section{4. 校院两级督导管理需注意的问题及建议}

校院两级督导管理, 不仅扩充了教学督导队伍, 弥补了学校教学督导各学科专业对口的不足, 并加大了教学监督和管理的力度, 为学校教学督导工作的全面展开创造了条件。建立两级督 导管理时，需要注意以下几个问题。

1. 尊重、关心、爱护教师, 有的放矢引导教师选择专业发展。

教学督导必须明确: 督是手段, 导才是目的。无论是新教师还是老教师, 教学督导的工作都 会给他们造成压力。此外, 教师还要接受学生听课的监督, 更形成多重压力。无论是校级还 
是二级学院的督导, 都要与教师多沟通, 从尊重、关心和爱护的角度指导教师的教学工作, 引导他主动要求推动自己的专业发展。若教学督导的思想或工作方法不够妥当, 其结果会适 得其反、欲速则不达。

2. 两级督导共同参与听课计划和活动，避免重复听课浪费时间和精力。

学校督导和二级学院教学督导要进行良好的沟通与协调, 共同参与听课计划和活动, 这样可 避免重复听课, 浪费时间和相关的资源以及给教师带来压力。建议采取同行互评或集体听课 形式，避免出现外行指导内行的弊端。

3. 及时沟通、反馈，给予教师客观评价，并有效引导。

教学效果的评价若出现差异, 势必给教师带来困惑, 不知如何改进。因此, 两级教学督导在 进行集体或同行听课后, 应及时交流, 对教师的评价尽量统一、客观, 并及时反馈有效引导, 避免了对同一个教师的评价意见出现过大的差异, 真正为教师的专业发展做出有效的专业引 导。

\section{5. 结语}

校院两级教学督导管理, 体现了教学监督和指导的针对性、专业性, 是当前高职院校教学督 导工作可行的模式。在今后的具体工作中，高职院校的教学督导应依据 “目标一致、各司其 职、良性互动、增强实效” 的原则, 进行两级督导管理, 并各有侧重地开展教育教学督导工 作，对促使教师专业发展必将起到十分积极的作用。

\section{References}

[1]. Thomas R. Guskey, Evaluating Profeessional Development [M]. Le Fang, Ying Zhang, Xijun Zhang, Shuxian Wang, translate in Beijing. China Light Industry Press,2005,p.2-30.

[2]. Qungao Li,Principles and implementation of Secondary Teaching Supervision in Colleges and Universities [J].Beijing Education (Higher Education Edition), (2006) No.9,p.47-48.

[3]. Hong Zhao, A probe into the effectiveness of Secondary Teaching Supervision in Colleges and departments in higher Vocational Colleges.Guangdong Vocational Techical Education Reserch [J], (2014) No.6, p.36-38.

[4]. Guofeng Xue, from "outside" to "inside": a probe into the Theory and practice of Teaching Supervision in Colleges and Universities [J]. Higher Education Research, (2014) NO.6, p.86.

[5]. Wenhong Song, A probe into the Supervision system of Chinese Colleges and Universities [J]. Journal of Xinjiang Normal University (Philosophy and Social Science Edition). (2013) No.6, p.101-108. 